\title{
Gene-Diet Interactions in Complex Disease: Current Findings and Relevance for Public Health
}

\author{
Lu Qi
}

Published online: 3 October 2012

(C) Springer Science+Business Media, LLC 2012

\begin{abstract}
Rates of obesity and related complex diseases, such as type 2 diabetes and cardiovascular disease, have climbed sharply over the past decades, in parallel with shift from principally more active lifestyle and nutritionally dense tradition diet to sedentary lifestyle and more energydense, western-pattern diet. During the past few years, advances in genotyping technology and in particular a number of large-scale genome-wide association studies have made great strides in unraveling the genetic basis of complex diseases; and the growing inventory of genetic variation is facilitating efforts to investigate gene-diet interactions. Understanding gene-diet interaction has the potential to promote diet modifications on the basis of genetic makeup. Several recent large-scale studies found reproducible evidence showing consumption of sugar sweetened beverages or dietary patterns might modulate genetic predisposition to obesity or cardiovascular disease. Analyses in randomized trials also showed that genetic markers for obesity, diabetes, or cardiovascular disease might modify the metabolic response to weight-loss diets. However, little of the knowledge about gene-diet interaction has been applied in public health practice; and opinion on how genetic testing services are offered and interpreted is still divided. This review will summarize recent findings regarding obesogenic diet, genetic susceptibility, and gene-diet interactions for obesity and related complex disorders and will
\end{abstract}

L. Qi $(\bowtie)$

Department of Nutrition, Harvard School of Public Health, 665 Huntington Ave,

Boston, MA 02115, USA

e-mail: nhlqi@channing.harvard.edu

L. Qi

Channing Division of Network Medicine,

Department of Medicine,

Brigham and Women's Hospital and Harvard Medical School,

Boston, MA, USA discuss the potential impact of these findings on public health practice.

Keywords Nutrition · Genetics · Gene-diet interaction · Obesity · Type 2 diabetes · Cardiovascular disease
Abbreviations
CVD cardiovascular disease
CHD coronary heart disease
GWAS genome-wide association study
BMI body mass index
FFQ food frequency questionnaires
HOMA-IR the homeostasis model
SNP single nucleotide polymorphism

\section{Introduction}

The prevalence of obesity and related complex diseases such as type 2 diabetes and cardiovascular disease has been rapidly increasing in the United States and worldwide, as people gain access to the trappings of sedentary lifestyle and obesogenic, Western-pattern diet $[1,2]$. It also has been noted considerable diversity exists in response to the diet and lifestyle transition at individual levels, suggesting that genetic makeup may also play a role in shaping the epidemic pattern of these disorders. With recent revolutionary advances in high-throughput genotyping technology, a large body of genome-wide association studies (GWAS) emerged and located hundreds of genomic variations related to risk of obesity, type 2 diabetes, and cardiovascular disease in the past few years $[3 \bullet \bullet, 4,5 \bullet \bullet, 6,7]$. In addition, recently emerging evidence from gene-diet interaction analyses in large-scale observational studies and randomized intervention trials favors the idea that the epidemic of obesity and related complex diseases may be not purely through lifestyle/diet or 
genetics, but interactions of these factors [3••, 4]. However, reproducible data supporting gene-diet interaction are still sparse; and little of the knowledge about gene-diet interaction has been applied in public health practice.

The aim of the present article is to review recent literature about obesogenic diet behavior and studies of interaction between genetic variation and diet in relation to obesity and related complex diseases including type 2 diabetes and cardiovascular disease. The review will particularly address the public health implication of the findings on gene-diet interaction, and discuss about the challenges lie in the studies and future directions.

\section{Obesogenic Diet Behavior and Genetic Susceptibility}

The transition from traditional, more active lifestyle and nutritionally dense tradition diet to an 'obesogenic' lifestyle featured by Western-pattern diet behavior and reduced physical activity in the past 30 years is believed a major driving force accounting for the epidemic of obesity and related diseases such as type 2 diabetes and cardiovascular disease $[5 \cdot \bullet, 6]$. A Western-pattern diet could be broadly defined by high intakes of foods characterized by having a high energy density as a result of a higher content of fat and a lower content of starchy and fiber-rich food, together with a high intake of sugar sweetened beverages; as well as low intakes of whole grain products, vegetables and fruits [7, 8]. For example, soft drinks and juices contain high concentrations of sugar and little other nutrient benefits. According to recent survey in the United States, between 1977 and 1996, the proportion of individuals consumption of average total calories from sugar sweetened beverages more than doubled, from $70 \mathrm{kcal}$ to $189 \mathrm{kcal}$ per day [9]. In addition, the fast-food culture is closely coupled to sugar sweetened beverages. Fast food, defined by the United States Department of Agriculture (USDA) as "food purchased in selfservice or carry-out eating places without wait service", is generally energy-dense, and tends to be high in fat, saturated fat, and glycemic index, yet poor in fiber. In the United States, consumption of fast food doubled from $20 \%$ in the 1970 s to $40 \%$ by $1995[10,11]$. Increased intake of sugar sweetened beverages and fast food not only add more energy, but may also corrupt neural functions of brain systems involved in nutrient sensing and regulation of energy balance [10]; which may jointly drive the development of obesity and related metabolic disorders [12]. Several decent reviews have revealed that unhealthy eating habits might promote weight gain and lead to elevated risk of obesity, type 2 diabetes, or cardiovascular diseases [13-15].

Classical genetic research such as family and twin studies have provided strong support for the genetic contribution to development of obesity, type 2 diabetes and cardiovascular disease; and the estimated heritability (a proportion of the phenotypic variance accounted for by genetic factors) for these complex disorders has shown a high proportion of the risk (up to $\sim 40-60 \%$ ) could be explained by genetic components [16-18]. Extensive effort has been made to discover the genomic loci related to these disorders; and such endeavor was recently accelerated by the breakthrough in genotyping technology and application of large-scale GWAS, which analyze millions of genetic variations spreading across human genome for their associations with the disease risk. Since the first wave of GWAS in 2007, the identified genomic loci for obesity, type 2 diabetes and cardiovascular disease have scaled up rapidly, reaching 30 to 50 for each disorder [19•, 20•]. While only a few of genetic variants were found to confer relatively strong effect on disease risk, such as the fat mass and obesity-associated gene $F T O$ for obesity [21, 22], the transcription factor 7-like 2 gene TCF7L2 for type 2 diabetes [23], and chromosome 9p21 for coronary heart disease [20•], most of the identified genetic variants, however, are related to very moderate effect and account for very small proportion of disease risk. For example, the difference in BMI associated with a single allele of established obesity genetic variant ranges from 0.06 to $0.39 \mathrm{~kg} / \mathrm{m}^{2}$; and the variance explained ranges from 0.01 to $0.34 \%$ [21]. Even though, when the accumulative genetic effects are considered, the difference in BMI between the extreme groups is not trivia. Moreover, because the currently identified genetic variants are all common in frequency, their population-attributable risk is considerable.

\section{Rationale for Studying Gene-Diet Interaction}

A presentation of gene-diet interactions should involve the concept of 'thrifty genotype' hypothesis, which was first proposed by the American geneticist James Neel in relation to an enhanced predisposition to type 2 diabetes and later extended to obesity $[24,25]$. According to the theory, feastor-famine conditions during human evolutionary development naturally selected for people who could store excess energy as body fat for later use. Thus, the ability to conserve calories by storing more fat offers a genetic advantage for selection of this genotype during periods of food scarcity. However, when individuals are faced with higher caloric loads in a modern context, carrying the thrifty genotype becomes a risk factor for obesity and related metabolic disorders. As such, genetic variations caused by adaptation to famine could have important health consequences in modern society; and obesity and related metabolic disorders may particularly affect those who are still adapted to former famine conditions: i.e. who carry thrifty genotype. Although the 'thrifty genotype' hypothesis was met with great skepticism [26, 27], it may partly explain currently epidemic of obesity and related diseases as consequence of interactions 
between genomic makeup and changed environment. There was a strong polarization of views that the changed environment is the principal cause for recent epidemic of obesity and related complex diseases. However, it is notable that, despite decades of plentiful food supplies, $\sim 70 \%$ of the population in the United States remains not obese, and $\sim 30 \%$ of the population remains lean [28]. It appears people vary in their inbuilt susceptibility, mainly determined by the genetic architecture, to the obesogenic effects of environmental factors such as diet.

\section{Gene-Diet Interactions in Observational Studies}

Gene-diet interaction occurs when the dietary effect on a person's health is conditional on specific genotype [3••, 29, 30]. Although the topic of gene-diet interaction has been extensively discussed, detection of such interaction in human studies was not fruitful in past decades, when most of the findings were not reproducible $[3 \cdot \bullet, 30,31]$. The previous studies are in general limited by relatively small sample size and cross-sectional design. Although GWAS have demonstrated the validity of studies with cross-sectional design in identification of disease-predisposing variants, which are less likely correlated with the potential confounders and free of reverse causation, inherent bias of cross-sectional analysis become paramount in testing gene-diet interaction. In addition, lack of replication is another serious flaw in these studies. An epidemiologic framework for evaluating genediet interaction has yet to be well established. Even though, several recent large-scale studies with prospective design and replication have emerged to shed light on the potential ways to plug gap in this fast-moving area.

A recent study [32••] tested interactions between CVDassociated genetic variants on chromosome 9p21 and dietary patterns in two study samples, including 8,114 individuals $(3,820 \mathrm{MI}$ cases) from the global INTERHEART study and 19,129 individuals (1,014 incident cases of CVD) from the prospective FINRISK study. It was found that a prudent diet score (high in raw vegetables, fruits, green leafy vegetables, nuts, desserts, and dairy products) significantly interact with 9 p21 variants. The genetic effects appeared strongest among those with the lowest prudent diet score (odd ratio $[\mathrm{OR}]=1.32$, and $95 \%$ confidence interval 1.18 1.48). The findings were roughly replicated in FINRISK study, in which stronger genetic effects on CVD were observed in individuals with low intakes of vegetables and fruits, which had the highest factor loadings for the prudent diet score. In our recent analysis, we assessed interactions between sugar sweetened beverage intake and obesity genetic susceptibility (evaluated on the basis of 32 BMIassociated loci) in relation to body mass index (BMI) and obesity risk [33••]. We employed a two-stage design consisting of three prospective cohorts - the Nurses' Health
Study (NHS) and Health Professional Follow-up Study (HPFS) in the discovery stage; and the Women Genome Health Study (WGHS) in the replication stage. We observed directionally consistent interaction between genetic susceptibility and sugar sweetened beverage in NHS and HPFS. In the combined samples of these cohorts, the increases in BMI $\left(\mathrm{kg} / \mathrm{m}^{2}\right)$ per 10 risk alleles were 1.00 for sugar sweetened beverage intake of $<1$ serving/month, 1.03 for $1-4$ servings/ month, 1.39 for $2-6$ servings/week, and 1.77 for $\geq 1$ servings/day ( $\mathrm{P}$ for interaction $<0.001$ ). The findings were successfully replicated in the WGHS, in which per 10 risk alleles were associated across the 4 categories of sugar sweetened beverage intake with $1.39,1.64,1.90$ and $2.53 \mathrm{~kg} / \mathrm{m}^{2}$ higher BMI ( $P$ for interaction $=0.001$ ). Taken together, these data provide reproducible evidence showing that interplay between disease-contributing genetic variants and diet may render certain individuals susceptible complex diseases.

\section{Gene-Diet Interactions in Diet Intervention Trials}

In observational studies, errors in dietary assessment may seriously limit the study power. This is particularly damaging when the size of gene-diet interaction is modest. Weighed diet records and multiple 24-h dietary recalls can assess dietary intake with high accuracy. However, these methods are usually not realistic in large population studies due to heavy respondent burden and poor compliance; and the most-widely used method for assessing long-term intake in epidemiological studies is food frequency questionnaire (FFQ) [34]. However, erroneous self-reporting using FFQ lowers the accuracy of the information and add huge amount of noise in analysis of gene-diet interaction. In addition, repeated dietary assessments may better capture long-term variance in diet intakes. However, such data are not available in the majority of existing cohorts. As an alternative approach, randomized intervention trials may offer an alternative setting for testing gene-diet interaction in longitudinal manner. In a randomized intervention trial, dietary factors are usually precisely defined and interventions are prescribed. In addition, randomization procedure minimizes the potential confounding effects that may seriously bias gene-diet interactions. A unique strength for gene-diet interaction studies in diet intervention trials is that, they may provide more direct evidence to instruct genetic-targeted diet modifications in future public health practice. However, most of existing diet intervention trials are relative small in size, the power for detection of moderate gene-diet interactions would be a major concern.

The Preventing Overweight Using Novel Dietary Strategies (Pounds Lost) trial is a clinical trial including in total of $811\left(\mathrm{BMI} \geq 25 \mathrm{~kg} / \mathrm{m}^{2}\right)$ and obese $\left(\mathrm{BMI} \geq 30 \mathrm{~kg} / \mathrm{m}^{2}\right)$ adult men and women who were randomly assigned to 1 of 4 
weight-loss diets varying in macronutrient contents (dietary fat, protein and carbohydrates) for 2 years [35]. Participants were 30 to 70 years of age. At 6 months, participants assigned to each diet had lost an average of $6 \mathrm{~kg}$, which represent $7 \%$ of their initial weight. The participants began to regain weight after 12 months. By 2 years, weigh loss remained similar in those who were assigned to diets with different components of protein, fat, and carbohydrates (low vs high). We recently tested hypothesis-driven gene-diet interactions in the Pounds Lost trial. In one analysis [36•], we found significant interaction between the insulin receptor substrate 1 gene IRS1 SNP rs2943641 and carbohydrate intake in relation to changes in insulin, HOMA-IR, and weight loss. In another analysis, we observed significant modification effects for intervention varying in dietary protein on 2-year changes in fat-free mass, whole body total percentage of fat mass, total adipose tissue mass, visceral adipose tissue mass, and superficial adipose tissue mass associated with FTO SNP rs1558902 [37•]. In addition, we have reported interactions of diet fat with the gastric inhibitory polypeptide receptor gene GIPR genotype in relation to insulin sensitivity [38•], and with the apolipoprotein A5 gene APOA5 genotype in relation to lipid profiles [39•]. These data clearly demonstrate considerable genetic heterogeneity in a variety of metabolic parameters in response to diet interventions, and lend support to personalized interventions according to genotype in the future, although the magnitude of the genetic effects may be not clinically relevant.

Replication remains a major challenge in gene-diet studies in the settings of clinical trials. The replication mechanisms adopt by previous genetic analyses in large cohorts or casecontrol studies are not applicable to intervention trials, because it is infeasible to hit upon trials with identical design. Even though, collaborations among clinical trials addressing similar diet interventions and outcomes own potential to be cross-validated. For example, we are now running gene-diet interaction tests in collaboration with another 2-year diet intervention trial, the Dietary Intervention Randomized Controlled Trial (DIRECT), which tests three different dietslow-fat, Mediterranean, or low-carbohydrate - on weight loss in 322 moderately obese participants [40]. The similar design of the DIRECT trial and the Pounds Lost trial builds excellent basis for replicating gene-diet interactions.

\section{Genetic-Targeted Public Health Practice}

While waiting for additional evidence for gene-diet interactions, it is time to consider an emerging important query: How the findings of gene-diet interactions could be translated to public health practice? Obesity, type 2 diabetes, and cardiovascular disease have been shown to be preventable by changing lifestyles and/or diet habits [35, 41]. Because the gene pool of a certain population has been relatively constant for many generations, modifications of dietary habits and lifestyles will remain a mainstream approach to prevent obesity and related diseases in public health practice. Genetic variation is not only important in determining an individual's susceptibility to diseases but also can influence the response to the diet modifications. The novel knowledge of gene-diet interaction will provide a strong scientific rationale for tailoring diet/lifestyle modifications to a personalized manner, which is different from the traditional one-size-fits-all approach [42, 43]. Data collected for gene-diet interactions would facilitate public health professionals to identify population subgroups with significantly different responses to diet, and the greatest hope in this context is the development of more efficient genetictargeted guideline of healthy diet for specific subpopulations. In line with this idea, the National Human Genome Research Institute recommends pursuing "genomic information to improve behavior change interventions" as part of its strategic vision for genomics [44]. As high-throughput genotyping and genome sequencing approaches are becoming cheaper, to provide genetic information to individuals on request will become feasible and grow to be a fertile ground for health-related services. Notably, commercial activity has been ahead of public health practice. The past few years have seen a steady increase in the number of companies that offer direct-to-consumer (DTC) genetic testing services [45]. It is still under tense debate whether individual gene testing would be provided by a clinical setting or by companies; and caution must be paid when interpreting results of such tests and instructing combination of the genetic information with an appropriate dietary regimen. In any cases, discoveries of gene-diet interactions need to be followed-up with functional and prospective validation before they can be applied to public health practice; and involvement of geneticists, nutritionists, and other healthcare professionals is essential.

To reduce levels of obesity and related complex diseases, interventions aimed at dietary modifications will not be successful on their own. Supporting action on the environment also is required at population levels. Our obesogenic environment provides increased opportunities for obtaining low-cost, energy-dense foods and sugared drinks. For example, as of 2002, there were more than 170,000 fast food restaurants and three million soft drink vending machines in the United States alone [46]. Such an obesogenic environment has considerably changed people's eating patterns. Other environmental factors, such as physical, social, cultural, and economical factors, also may affect dietary behavior [47]. In addition, modern sedentary activities also promote overconsumption of unhealthy food. This is particularly the case with television watching and short sleeping [48-50]. Future genetictargeted public health practice would take these highlevel factors into consideration as well. 


\section{Conclusions}

Unhealthy diet is a key risk factor for obesity and related complex diseases, such as type 2 diabetes and cardiovascular disease. In the past few years, genetic research has made great strides in identification of genetic factors that contribute to these disorders. It is widely acknowledged that complex diseases probably arise through a web of interplays between genetic and environmental factors, including diet. However, there is remarkably little evidence of gene-diet interaction from human studies. Recent results from largescale studies highlight that dietary patterns or consumption of sugar-sweetened beverages may modify the genetic predisposition to cardiovascular risk or obesity. More welldesigned studies on gene-diet interactions are underway.

The advances in the field have raised a fundamental question about how to incorporate the novel knowledge about gene-diet interactions into genetic-targeted public health practice. Advance in high-throughput genotyping technology is facilitating offer of direct-to-consumer genetic testing services, and raised great hope and expectations that genetic testing will pave the way to personalized prevention. In the light of such a trend, debates about how to establish preventive genomics-based genetic testing in a medically and socially responsible way have just begun. In addition, curbing the epidemics of obesity and related disorders calls for not only changes in diet habits but also changes in policy, physical and social environment, as well as lifestyles. In the following years, public health practice will not be able to ignore the impact of genetics and gene-diet interactions, although it is still a long journey to better appreciate their relevance to the practice of preventive approaches for delaying onset of diseases, diminishing their severity, and optimizing human health.

Acknowledgments L. Qi is supported by National Institutes of Health grants DK091718 and HL071981, American Heart Association Scientist Development Award, United States - Israel Binational Science Foundation (Grant 2011036), and the Boston Obesity Nutrition Research Center (DK46200).

Disclosures L. Qi has received compensation from GenoVive for serving as a consultant and from Kellogg for lectures, including service on speakers' bureaus.

\section{References}

Papers of particular interest, published recently, have been highlighted as:

- Of importance

-. Of major importance

1. Zimmet P, Alberti KG, Shaw J. Global and societal implications of the diabetes epidemic. Nature. 2001;414:782-7.
2. Haslam DW, James WP. Obesity. Lancet. 2005;366:1197-209.

3. -. Qi L, Cho YA. Gene-environment interaction and obesity. Nutr Rev. 2008;66:684-94. This paper comprehensively reviews evidence related to gene-environment interactions in relation to obesity risk.

4. Hetherington MM, Cecil JE. Gene-environment interactions in obesity. Forum Nutr. 2010;63:195-203.

5. •- Popkin BM, Adair LS, Ng SW. Global nutrition transition and the pandemic of obesity in developing countries. Nutr Rev. 2012;70:3-21. This article comprehensively reviews the impact of global nutrition transition on increase in obesity.

6. Guyenet SJ, Schwartz MW. Clinical review: regulation of food intake, energy balance, and body fat mass: implications for the pathogenesis and treatment of obesity. J Clin Endocrinol Metab. 2012;97:745-55.

7. Bhupathiraju SN, Tucker KL. Coronary heart disease prevention: nutrients, foods, and dietary patterns. Clin Chim Acta. 2011;412:1493-514.

8. Odegaard AO, Koh WP, Yuan JM, Gross MD, Pereira MA. Western-style fast food intake and cardiometabolic risk in an eastern country. Circulation. 2012;126:182-8.

9. Nielsen SJ, Popkin BM. Changes in beverage intake between 1977 and 2001. Am J Prev Med. 2004;27:205-10.

10. Isganaitis E, Lustig RH. Fast food, central nervous system insulin resistance, and obesity. Arterioscler Thromb Vasc Biol. $2005 ; 25: 2451-62$.

11. Guthrie JF, Lin BH, Frazao E. Role of food prepared away from home in the American diet, 1977-78 versus 1994-96: changes and consequences. J Nutr Educ Behav. 2002;34:140-50.

12. Berthoud HR. The neurobiology of food intake in an obesogenic environment. Proc Nutr Soc. 2012;1-10.

13. Bezerra IN, Curioni C, Sichieri R. Association between eating out of home and body weight. Nutr Rev. 2012;70:65-79.

14. Weed DL, Althuis MD, Mink PJ. Quality of reviews on sugarsweetened beverages and health outcomes: a systematic review. Am J Clin Nutr. 2011;94:1340-7.

15. Astrup A, Dyerberg J, Selleck M, Stender S. Nutrition transition and its relationship to the development of obesity and related chronic diseases. Obes Rev. 2008;9 Suppl 1:48-52.

16. Patel RS, Ye S. Genetic determinants of coronary heart disease: new discoveries and insights from genome-wide association studies. Heart. 2011;97:1463-73.

17. O'Rahilly S, Barroso I, Wareham NJ. Genetic factors in type 2 diabetes: the end of the beginning? Science. 2005;307:370-3.

18. Yang W, Kelly T, He J. Genetic epidemiology of obesity. Epidemiol Rev. 2007;29:49-61.

19. - McCarthy MI. Genomics, type 2 diabetes, and obesity. N Engl J Med. 2010;363:2339-50. This article comprehensively reviews the progression of genetic research in obesity and type 2 diabetes.

20. • O'Donnell CJ, Nabel EG. Genomics of cardiovascular disease. N Engl J Med. 2011;365:2098-109. This article comprehensively reviews the progression of genetic research in cardiovascular disease.

21. Speliotes EK, Willer CJ, Berndt SI, Monda KL, Thorleifsson G, Jackson AU, et al. Association analyses of 249,796 individuals reveal 18 new loci associated with body mass index. Nat Genet. 2010;42:937-48.

22. Wen W, Cho YS, Zheng W, Dorajoo R, Kato N, Qi L, et al. Metaanalysis identifies common variants associated with body mass index in east Asians. Nat Genet. 2012;44:307-11.

23. Saxena R, Elbers CC, Guo Y, Peter I, Gaunt TR, Mega JL, et al. Large-scale gene-centric meta-analysis across 39 studies identifies type 2 diabetes loci. Am J Hum Genet. 2012;90:410-25.

24. Neel JV. Diabetes mellitus: a "thrifty" genotype rendered detrimental by "progress"? Am J Hum Genet. 1962;14:353-62.

25. Chakravarthy MV, Booth FW. Eating, exercise, and "thrifty" genotypes: connecting the dots toward an evolutionary understanding of modern chronic diseases. J Appl Physiol. 2004;96:3-10. 
26. Benyshek DC, Watson JT. Exploring the thrifty genotype's foodshortage assumptions: a cross-cultural comparison of ethnographic accounts of food security among foraging and agricultural societies. Am J Phys Anthropol. 2006;131:120-6.

27. Speakman JR. A nonadaptive scenario explaining the genetic predisposition to obesity: the "predation release" hypothesis. Cell Metab. 2007;6:5-12.

28. Flegal KM, Carroll MD, Ogden CL, Curtin LR. Prevalence and trends in obesity among US adults, 1999-2008. JAMA. 2010;303:235-41.

29. Qi L, Hu FB, Hu G. Genes, environment, and interactions in prevention of type 2 diabetes: a focus on physical activity and lifestyle changes. Curr Mol Med. 2008;8:519-32.

30. Qi L, Liang J. Interactions between genetic factors that predict diabetes and dietary factors that ultimately impact on risk of diabetes. Curr Opin Lipidol. 2010;21:31-7.

31. Perusse L, Bouchard C. Gene-diet interactions in obesity. Am J Clin Nutr. 2000;72:1285S-90S.

32. • Do R, Xie C, Zhang X, Mannisto S, Harald K, Islam S, et al. The effect of chromosome 9p21 variants on cardiovascular disease may be modified by dietary intake: evidence from a case/control and a prospective study. PLoS Med. 2011;9:e1001106. This paper describes an interaction between gene identified in genome-wide association study and dietary patterns in relation to CHD risk.

33. •• Qi Q, Chu A, Kang J, Jensen M, Curhan G, Pasquale L, Ridker P, Hunter D, Willett W, Rimm E, et al. Sugar-sweetened beverages and genetic predisposition to obesity (2012). N Engl J Med. 2012. This paper describes consistent evidence showing an interaction between obesity genetic susceptibility and intake of sugarsweetened beverage in three prospective cohorts.

34. Tucker KL. Assessment of usual dietary intake in population studies of gene-diet interaction. Nutr Metab Cardiovasc Dis. 2007; 17:74-81.

35. Sacks FM, Bray GA, Carey VJ, Smith SR, Ryan DH, Anton SD, et al. Comparison of weight-loss diets with different compositions of fat, protein, and carbohydrates. N Engl J Med. 2009;360:859-73.

36. • Qi Q, Bray GA, Smith SR, Hu FB, Sacks FM, Qi L. Insulin receptor substrate 1 gene variation modifies insulin resistance response to weight-loss diets in a 2-year randomized trial: the Preventing overweight using novel dietary strategies (POUNDS LOST) trial. Circulation. 2012;124:563-71. A study testing hypothesis-driven gene-diet interaction in randomized diet intervention trial.

37. - Zhang X, Qi Q, Zhang C, Hu FB, Sacks FM, Qi L. FTO genotype and 2-year change in body composition and fat distribution in response to weight-loss diets: the POUNDS LOST Trial. Diabetes. 2012. A study testing hypothesis-driven gene-diet interaction in randomized diet intervention trial.
38. - Qi Q, Bray GA, Hu FB, Sacks FM, Qi L. Weight-loss diets modify glucose-dependent insulinotropic polypeptide receptor rs2287019 genotype effects on changes in body weight, fasting glucose, and insulin resistance: the preventing overweight using novel dietary strategies trial. Am J Clin Nutr. 2011;95:506-13. A study testing hypothesis-driven gene-diet interaction in randomized diet intervention trial.

39. • Zhang X, Qi Q, Bray GA, Hu FB, Sacks FM, Qi L. APOA5 genotype modulates $2-y$ changes in lipid profile in response to weight-loss diet intervention: the Pounds Lost Trial. Am J Clin Nutr. 2012. A study testing hypothesis-driven gene-diet interaction in randomized diet intervention trial.

40. Shai I, Schwarzfuchs D, Henkin Y, Shahar DR, Witkow S, Greenberg I, et al. Weight loss with a low-carbohydrate, Mediterranean, or lowfat diet. N Engl J Med. 2008;359:229-41.

41. Tuomilehto J, Lindstrom J, Eriksson JG, Valle TT, Hamalainen H, Ilanne-Parikka $\mathrm{P}$, et al. Prevention of type 2 diabetes mellitus by changes in lifestyle among subjects with impaired glucose tolerance. N Engl J Med. 2001;344:1343-50.

42. Simopoulos AP. Nutrigenetics/nutrigenomics. Annu Rev Public Health. 2010;31:53-68.

43. Offit K. Personalized medicine: new genomics, old lessons. Hum Genet. 2011;130:3-14.

44. Green ED, Guyer MS. Charting a course for genomic medicine from base pairs to bedside. Nature. 2011;470:204-13.

45. Howard HC, Borry P. To ban or not to ban? Clinical geneticists' views on the regulation of direct-to-consumer genetic testing. EMBO Rep 2012

46. Chopra M, Galbraith S, Darnton-Hill I. A global response to a global problem: the epidemic of overnutrition. Bull World Health Organ. 2002;80:952-8.

47. Giskes K, Kamphuis CB, van Lenthe FJ, Kremers S, Droomers M, Brug J. A systematic review of associations between environmental factors, energy and fat intakes among adults: is there evidence for environments that encourage obesogenic dietary intakes? Public Health Nutr. 2007;10:1005-17.

48. Chapman CD, Benedict C, Brooks SJ, Birgir SH. Lifestyle determinants of the drive to eat: a meta-analysis. Am J Clin Nutr 2012;96:492-7.

49. Qi Q, Li Y, Chomistek AK, Kang JH, Curhan GC, Pasquale LR, Willett WC, Rimm EB, Hu FB, Qi L. Television watching, leisuretime physical activity and the genetic predisposition in relation to body mass index in women and men. Circulation. 2012.

50. Lissner L, Lanfer A, Gwozdz W, Olafsdottir S, Eiben G, Moreno LA Santaliestra-Pasias AM, Kovacs E, Barba G, Loit HM, et al. Television habits in relation to overweight, diet and taste preferences in European children: the IDEFICS study. Eur J Epidemiol. 2012. 